\title{
Comparative mitogenomics, phylogeny and evolutionary history of Leptogorgia (Gorgoniidae)
}

\author{
Poliseno Angelo ${ }^{1}$, Feregrino Christian ${ }^{1}$, Sartoretto Stephane ${ }^{2}$, Aurelle Didier ${ }^{3}$, Woerheide Gert 1, 4, 5, \\ McFadden Catherine S. ${ }^{6}$, Vargas Sergio ${ }^{1,}{ }^{*}$
}

${ }^{1}$ Ludwig Maximilians Univ Munchen, Dept Earth \& Environm Sci, Palaeontol \& Geobiol, Richard

Wagner Str 10, D-80333 Munich, Germany.

2 IFREMER, CS 20330, F-83507 La Seyne Sur Mer, France.

3 Univ Avignon, Aix Marseille Univ, CNRS, IRD,IMBE, F-13007 Marseille, France.

${ }^{4}$ Ludwig Maximilian Univ Munchen, GeoBioctr, Richard Wagner Str 10, D-80333 Munich, Germany.

${ }^{5}$ Bayer Staatssammlung Palaontol \& Geol, Richard Wagner Str 10, D-80333 Munich, Germany.

${ }^{6}$ Harvey Mudd Coll, Dept Biol, Claremont, CA 91711 USA.

*Corresponding author : Sergio Vargas, email address : sergio.vargas@Imu.de

a.poliseno@Irz.uni-muenchen.de ; christian.feregrino@unibas.ch ; Stephane.Sartoretto@ifremer.fr ; didier.aurelle@univ-amu.fr ; woerheide@Imu.de ; mcfadden@g.hmc.edu

\begin{abstract}
:
Molecular analyses of the ecologically important gorgonian octocoral genus Leptogorgia are scant and mostly deal with few species from restricted geographical regions. Here we explore the phylogenetic relationships and the evolutionary history of Leptogorgia using the complete mitochondrial genomes of six Leptogorgia species from different localities in the Atlantic, Mediterranean and eastern Pacific as well as four other genera of Gorgoniidae and Plexauridae. Our mitogenomic analyses showed high interspecific diversity, variable nucleotide substitution rates and, for some species, novel genomic features such as ORFs of unknown function. The phylogenetic analyses using complete mitogenomes and an extended mtMutS dataset recovered Leptogorgia as polyphyletic, and the species considered in the analyses were split into two defined groups corresponding to different geographic regions, namely the eastern Pacific and the Atlantic-Mediterranean. Our phylogenetic analysis based on mtMutS also showed a clear separation between the eastern Atlantic and South African Leptogorgia, suggesting the need of a taxonomic revision for these forms. A time-calibrated phylogeny showed that the separation of eastern Pacific and western Atlantic species started ca. 20 Mya and suggested a recent divergence for eastern Pacific species and for L. sarmentosa-L. capverdensis. Our results also revealed high inter-specific diversity among eastern Atlantic and South African species, highlighting a potential role of the geographical diversification processes and geological events occurring during the last $30 \mathrm{Ma}$ in the Atlantic on the evolutionary history of these organisms.
\end{abstract}




\section{Graphical abstract}

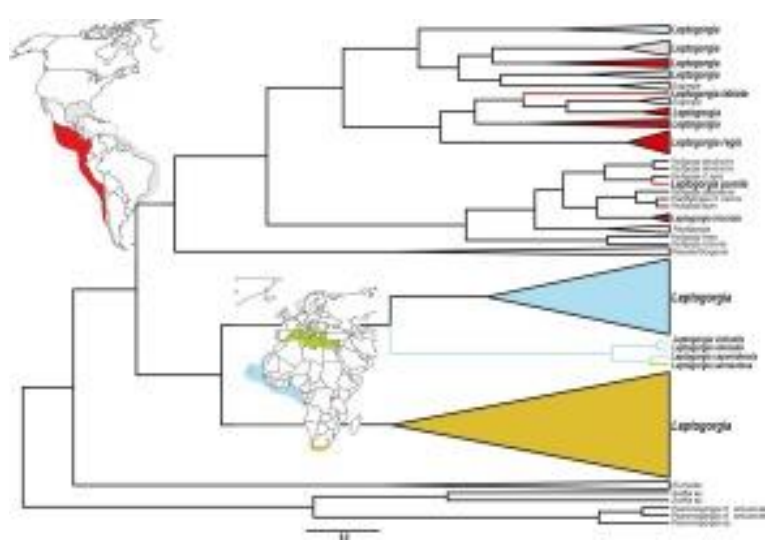

\section{Highlights}

Complete mitogenomes of twelve shallow-water gorgonian species. A fully-supported mitogenomic phylogeny recovered a polyphyletic Leptogorgia. - Phylogenetic divergence among geographically restricted Leptogorgia lineages. Genetic discontinuity between the eastern Atlantic and South African Leptogorgia. - Eastern Atlantic Leptogorgia requires a taxonomic revision.

Keywords : Octocorals, Gorgonians, Leptogorgia, Mitogenome, Molecular phylogeny, Evolutionary history 


\section{Introduction}

The genus Leptogorgia includes more than 50 valid species with a wide geographic and bathymetric distribution. One third of the species is distributed in the eastern Pacific, EP (Breedy and Guzman, 2007), more than 30 species were reported in the Atlantic (Grasshoff, 1988) and only two species have been described from the Mediterranean (Carpine and Grasshoff, 1975) and subarctic (Williams and Lindo, 1997). The identification and classification of Leptogorgia is extremely difficult due to their morphological homogeneity (Williams and Lindo, 1997), the phenotypic plasticity observed in the genus (Breedy and Guzman, 2007) and the lack of distinct diagnostic morphological characters (Bayer, 1961; Sánchez, 2007) that can be used to differentiate between species. In addition, the systematic history of the genus is complex. The current concept of Leptogorgia includes species formerly classified as Lophogorgia (Milne Edwards and Haime, 1857) or Leptogorgia (Milne Edwards and Haime, 1857), two genera that have been synonymized and segregated multiple times by different authors (Verrill, 1868; Bayer, 1956,1961; Grasshoff, 1988). According to Bayer (1961), Leptogorgia included species with short disk-spindles in the outer portion of the coenenchyme and uniformly sculptured spindles in the inner part, and was mostly restricted to the Caribbean and Western Atlantic waters. Lophogorgia was used to group eastern Atlantic-Mediterranean and eastern Pacific species with symmetrically sculptured spindles that are not fused into a disk-like form and anthocodial sclerites that are usually flat rods. However, the morphological distinction between Lophogorgia and Leptogorgia was later questioned by Grasshoff (1988) based on his observation of transitional forms between the two genera. 
Molecular studies on gorgoniid octocorals have shown phylogenetic divergence between eastern Pacific and Caribbean species of Leptogorgia (Aguilar and Sánchez, 2007; Vargas et al. 2014; Ament-Velásquez et al. 2016) pointing towards a possible separation of these species groups in agreement with previous morphological hypotheses. Moreover, analyses including eastern Atlantic (EA) Leptogorgia representatives (Sánchez, 2007) clearly indicated the need of a systematic re-evaluation of the genus. Molecular methods such as DNA barcoding have been widely used to complement traditional octocoral taxonomy (Sánchez, 2007; Breedy et al. 2012; McFadden and van Ofwegen, 2012, 2013; Bryce et al. 2015) and to provide an independent source of evidence that can be used to test morphologybased systematic hypotheses (see e.g. Wirshing et al. 2005; Vargas et al. 2010, 2014). Single mitochondrial protein-coding genes, especially partial $m t M u t S$ sequences, are among the most commonly used molecular markers for phylogenetic inference in octocorals (McFadden et al. 2006, 2011). Yet the resolution of single mitochondrial markers is known to be low among members of this group, and in general among non-bilaterian metazoans (Huang et al. 2008). Despite the relative simplicity of obtaining complete mitochondrial genomes (mitogenomics) using either Sanger or Next Generation Sequencing (NGS) technologies (Maricic et al. 2010; Timmermans et al. 2010), the recovery of mitogenomes for phylogenetic research remains only superficially explored in octocorals. Indeed, within metazoans only $30 \%$ of the complete mitochondrial genomes publicly available belong to invertebrates (Bernt et al. 2013) and among the ca. 3000 octocoral species described to date only $1 \%$ have been considered in mitogenomic analyses (Park et al. 2011, 2012; Brockman and McFadden, 2012; Figueroa and Baco, 2015). Here, we present the complete mitochondrial genomes of six Leptogorgia species representing the main geographic regions where this genus is distributed, namely the eastern Pacific, Mediterranean and Atlantic, and use them to infer a robust phylogeny of the genus and to clarify its systematics. We also use an extended dataset based on the mtMutS marker to provide divergence time estimates for different lineages of Leptogorgia and discuss the potential role of different geological events on the diversification of this genus through history.

\section{Material and Methods}

\subsection{Sampling, DNA extraction, amplification and sequencing}

Samples were collected by SCUBA diving from shallow waters $(5-40 \mathrm{~m})$ in the Mediterranean, eastern Atlantic and eastern Pacific, vouchers are deposited in the Bavarian 
State Collection of Palaeontology and Geology (SNSB-BSPG) (see Supplementary Table S1). The western Atlantic specimen (USNM 1437444) was collected using a Remotely Operated Vehicle (ROV) in the Gulf of Mexico at a depth of about $60 \mathrm{~m}$. Genomic DNA was extracted from the tissue of a single individual using a modified CTAB method (Porebski et al. 1997). Except for Eunicella cavolini, Muricea crassa and Muricea purpurea, for which complete mitochondrial genomes were obtained from the sequencing of short-insert libraries, the remaining mitogenomes (i.e. Eugorgia mutabilis, Eunicella albicans, Pacifigorgia cairnsi, Leptogorgia alba, Leptogorgia capverdensis, Leptogorgia gaini, Leptogorgia sarmentosa, Leptogorgia cf. palma and Leptogorgia sp.) were sequenced using standard primer walking procedures (e.g. McFadden et al. 2011; Brockman and McFadden, 2012). Depending on the quality and yield of the extracted DNA, amplification was performed using two-step or three-step PCRs. The two-step programme included a denaturation step at $95{ }^{\circ} \mathrm{C}$ for $3 \mathrm{~min}(1 \mathrm{cycle})$ followed by 35 cycles at $95{ }^{\circ} \mathrm{C}$ for $30 \mathrm{~s}, 66{ }^{\circ} \mathrm{C}$ for $4 \mathrm{~min}$ and $30 \mathrm{~s}$ and a final extension at $66^{\circ} \mathrm{C}$ for $10 \mathrm{~min}$. Three-step PCRs were done using annealing temperatures specific for the primer pair used, denature and extensions temperature were $95{ }^{\circ} \mathrm{C}$ and $72{ }^{\circ} \mathrm{C}$; the extension time used was determined assuming a polymerase processivity of $1 \mathrm{~kb} / \mathrm{min}$. The primers utilised for the amplification of complete mitochondrial genomes are available in the Supplementary Materials (Suppl. Table S2). Specific primers were designed in order to bridge the gaps in some mitochondrial intergenic spacers (e.g. Nad5-Nad4) and protein coding genes (i.e. Nad2 and mtMutS) in Eunicella albicans and Pacifigorgia cairnsi (see Suppl. Table S3). For standard three-step PCR, the annealing temperature and the extension time were adjusted according to the primer pairs used and the expected amplicon lengths. PCR was performed in $12.5 \mu \mathrm{L}$ volumes following the GoTaq ${ }^{\circledR} \mathrm{G} 2$ Flexi DNA Polymerase (Promega, Madison, WI, USA) or the Crimson LongAmp ${ }^{\mathrm{TM}}$ Taq DNA Polymerase (New England BioLabs) protocols. PCR products were purified by precipitation with one volume $20 \%$ (w/v) polyethyleneglycol 8000 in $2.5 \mathrm{molL}^{-1} \mathrm{NaCl}$ and sequenced directly using the BigDye 3.1 chemistry (Applied Biosystems, Foster City, CA, USA) with same primers used for PCR or by primer walking. All mitogenome sequences have been deposited in the National Center for Biotechnology Information under accession numbers KY553145 and KY559404-KY559412. MtMutS sequences of the South African and Eastern Atlantic Leptogorgia have been deposited under accession numbers KY236030-KY236043 and KY683791-KY683798.

For the eastern Atlantic and South African specimens for which mitogenomes were not sequenced, the 5 ' end of the $m t M u t S$ gene ( $730 \mathrm{bp})$ was amplified using the primers 
ND42599F (France and Hoover, 2002) and Mut3458R (Sánchez et al. 2003), following standard protocols.

\subsection{Mitogenomes assembly, annotation and comparison}

Sequences were checked, assembled and annotated using GENEIOUS 8.1.7 (Kearse et al. 2012). Mitogenome annotation was initially performed with the ORF nder function implemented in GENEIOUS and was later corroborated by comparison with other octocoral mitogenomes available on GenBank. Nucleotide composition, GC content and pairwise genetic distances were calculated in MEGA 6.06 (Tamura et al. 2013). Nucleotide diversity in the protein coding genes was assessed with DnaSP 5.10.1 (Librado and Rozas, 2009). The presence of DNA tandem repeats was detected with the Tandem Repeats Finder server 4.08 (Benson, 1999) available at https://tandem.bu.edu/trf/trf.html.

\subsection{NGS and mitogenome assembly}

Genomic DNA library for Eunicella cavolini was prepared using standard library preparation procedures for Illumina sequencing. The library was multiplexed and sequenced in a single lane of an Illumina HiSeq (100 bp paired end) at the Gene Center of the Ludwig Maximilians Universität. Quality was assessed with FastQC (Andrews, 2010). Low quality reads and Illumina TruSeq adaptors were trimmed with Trimmomatic 0.3.2 using Trinity RNA-Seq 2.0.6 (Grabherr et al. 2011) and the same program was utilised for de novo assembly of the mitogenomes.

\subsection{Phylogenetic analyses of the mitogenomic dataset}

The complete mitochondrial genomes obtained were aligned with those of other octocorals available in Genbank using MUSCLE with default parameters (Edgar, 2004). Due to the existence of different mitochondrial gene arrangements in Octocorallia, protein-coding genes were extracted from each mitochondrial genome and aligned to produce single-gene matrices that were concatenated to obtain an alignment including 14 mitochondrial protein-coding genes. Sequence annotation was not consistent within the downloaded mitogenomes and some differences were reported in the Coding DNA Sequences (CDSs). Therefore, before concatenation, all the alignments were visually inspected and in some cases, the mitochondrial protein-coding genes were trimmed at one or both of their 5' and 3' ends. The concatenated alignment was used for mito-phylogenetic analyses of the subclass Octocorallia. The best substitution models and partition schemes were selected with PartitionFinder 1.1.1 
(Lanfear et al. 2012) using the Bayesian Information Criterion (BIC), and the greedy algorithm, respectively. Maximum Likelihood (ML) and Bayesian analyses were performed in RAxML 7.2.8 and MrBayes 3.2.5 (Ronquist and Huelsenbeck, 2003) respectively. The ML tree was inferred using a GTR+G substitution model and the support for the estimated tree was assessed using 1000 bootstrap pseudo-replicates. For the Bayesian analysis, the Metropolis-coupled Markov chain Monte Carlo (MCMCMC) simulation different partitioning schemes (see Suppl. Table S4) were used and the chain ran for $10,000,000$ generations, sampling every 1000 steps; $25 \%$ of the sampled trees were discarded as burn-in. The variation rates among the different partitions were allowed to change through a flat Dirichlet prior distribution. The nucleotide frequencies, substitution rates, gamma shape and invariant-sites proportion were unlinked. The analysis was allowed to run until the average standard deviation of the split frequencies (ASDSF) was below 0.009. In addition, MCMCMC convergence was assessed with Tracer 1.6 (Rambaut et al. 2014) and the trace plots showing evidence of convergence are provided in the Supplementary File S1. The resulting mitogenomic phylogeny was rooted using the Calcaxonian-Pennatulacea species as outgroup. All the alignments used in this study are available at Open Data LMU (DOI: doi:10.5282/ubm/data.99).

\subsection{Extended Bayesian phylogenetic analyses, fossil calibration and divergence time} estimation

We used a dataset including 114 mtMutS sequences (109 gorgoniids and 5 plexaurids) and 725 nucleotide positions (see Suppl. Table S1 for the list of samples used). All the sequences were aligned with MUSCLE using the default options; the alignment generated is available at Open Data LMU (DOI: doi:10.5282/ubm/data.99). Divergence time estimation was done using an uncorrelated lognormal relaxed clock model as implemented in BEAST 2.3.2 (Bouckaert et al. 2014). The best-fit substitution model $(\mathrm{HKY}+\mathrm{I}+\mathrm{G})$ was selected with the AIC in jModelTest, and the Yule tree prior speciation model was chosen for divergence time estimation analyses (Aldous, 2001; Gernhard, 2008). For molecular dating, the age of crown Eunicella was constrained using a lognormal prior distribution with an offset of 28.4 Ma, mean $=1$ and standard deviation $=1$. Among gorgonians, fossils are rare and those found are difficult to assign to genera with confidence due to the lack of diagnostic characters among sclerites (Kocurko and Kocurko, 1992). Gorgonian fossils have been reported from Texas (Middle Eocene) (Giammona and Robert, 1980), Poland (Upper Cretaceous) (Malecki, 1982), Mississippi (Lower Oligocene) (Kocurko and Kocurko, 1992) and recently from Wales 
(Lower Ordovician) (Cope, 2005). The fossil assemblages from the Red Bluff Formation in Mississippi —dated to the Lower Oligocene (28.4-33.9 Mya) - represent one of the most diverse collections found from a single location with about 1000 well-preserved sclerites. The majority of the sclerites described belong to Plexauridae and Gorgoniidae genera and among them balloon-club sclerites, belonging to the genus Eunicella, can be clearly identified (Kocurko and Kocurko, 1992). Fossil Eunicella sclerites were therefore used as a single calibration point in our molecular dating analyses. For molecular dating, the MCMC ran for two independent runs of 10 million generations, sampling every 1000 generations, until the Effective Sample Size (ESS) for all parameters was >100. ESS and convergence onto the posterior distribution were assessed using Tracer 1.6 (Rambaut et al. 2014). Evidence of MCMC convergence is shown in the Supplementary File S2. Among the 10000 trees obtained, 10\% were discarded as burn-in and the maximum clade credibility (MCC) tree with mean divergence times for the nodes was summarized in TreeAnnotator. Influence of the priors on the posterior distribution estimates was assessed by re-running the same analysis using an 'empty' dataset, allowing sampling from the priors only. The trace estimates and a comparison between the marginal prior and posterior densities is shown in the Supplementary File S3.

\section{Results}

\subsection{Mitogenomes}

The complete mitogenomes of Eugorgia mutabilis, Eunicella albicans, Eunicella cavolini and Pacifigorgia cairnsi are described in the Supplementary File S4, whereas the complete mitogenomes of Muricea crassa and Muricea purpurea have been communicated elsewhere (see Poliseno et al. 2016). Concerning Leptogorgia species, the mitogenome size ranged between 18,722 bp in L. sarmentosa and L. capverdensis to 19,682 bp in L. gaini. The circular maps of all mitochondrial genomes here sequenced are shown in the Supplementary File S5. All species investigated have the same gene arrangement (type "A"; see Brockman and McFadden 2012) including 14 protein-coding genes, 2 ribosomal RNA subunits (12S and $16 \mathrm{~S})$ and one methionine tRNA gene (tRNA $\left.{ }^{\mathrm{Met}}\right)$. Among the protein-coding genes, four were encoded in the light strand (Cox2, Atp8, Atp6 and Cox3) and ten in the heavy strand (Cox1, Nad1, Cob, Nad6, Nad3, Nad4L, mtMutS, Nad2, Nad5 and Nad4). For L. sarmentosa and L. alba the CDS spans $79.1 \%$ and $78.76 \%$ of the mitogenome, respectively. The CDS for $L$. capverdensis, L. cf. palma and Leptogorgia sp. Represented 79.24\%, 79.06\% and $78.75 \%$ of 
the genome, whereas for L. gaini the CDS spans $75.26 \%$ of the mitochondrial genome. GC content ranged from $36.8 \%$ (L. alba, L. capverdensis and L. sarmentosa) to $37.1 \%$ (L. gaini) (Figure 1A). Only one case of gene overlap was observed, with the loci Nad2 and Nad5 overlapping by $13 \mathrm{bp}$. All the other genes were separated by intergenic regions (IGRs). The lengths of the longest non-coding regions differed among species. For Leptogorgia sp. and $L$. alba the longest IGRs were located between Coxl and 12S rRNA (131-132 bp) and between Nad5 and Nad4 (204 bp) respectively. In L. gaini the longest IGR was between Cob and Nad6 (1041 bp); this region included a tandem repeat and an unidentified putative open reading frame (ORF) for which the blastx search of NCBI did not provide any high scoring hits. For L. alba, L. sarmentosa, L. gaini and Leptogorgia sp. the shortest IGR (4 bp) occurred between 12S rRNA and Nad1. Leptogorgia capverdensis, Leptogorgia sp. and L. palma had a mitogenomic structure similar to that of $L$. sarmentosa and L. alba. In particular, the mitogenomes of $L$. capverdensis and L. sarmentosa were almost identical with a genetic distance less than $0.05 \%$. Polymorphic sites (excluding gaps or missing data) in the mitochondrial coding sequences of the five Leptogorgia species were $5.7 \%$ of the total, and the most variable genes were $\mathrm{Nad} 5, \mathrm{Nad} 4, \mathrm{Cob}$ and $m t \mathrm{MutS}$ (see Figure 1B). The start codon ATG was the same for all the protein-coding genes; stop codons TAA and TAG were predominant with the exception of Coxl which terminates with CTTT. The only species with a standard stop codon (TAA) for Coxl were Leptogorgia alba and Leptogorgia sp.

\subsection{Mito-phylogeny}

The trees obtained with ML and Bayesian methods have the same topology and the separation of the species into two main groups is supported. One clade (I) contains the scleraxonian genera (Corallium, Paracorallium, Paragorgia and Sibobagorgia) and the alcyonaceans Anthomastus sp. and Paraminabea aldersladei. The second clade (II) comprised Briareum asbestinum and 26 Alcyoniina specimens further divided into the Alcyoniidae, Nephtheidae, and "holaxonian" groups (Figure 2). The use of calcaxonian species as outgroup has most likely affected the overall topology of the tree. Indeed, Briareum asbestinum usually falls basal to both the Calcaxonia-Pennatulacea and AlcyoniinaHolaxonia clades (see e.g. McFadden et al. 2006 or Park et al. 2012). The "holaxonian" group includes members of the families Gorgoniidae and Plexauridae. Leptogorgia was split into two clades (1 and 2). L. sarmentosa and the eastern Atlantic species (L. gaini, L. capverdensis and L. palma) formed a well-supported clade (1) sister to a clade (2) including 
Pseudopterogorgia bipinnata, Pacifigorgia cairnsi, Eugorgia mutabilis, Leptogorgia sp. and Leptogorgia alba.

\subsection{MtMutS phylogeny and pairwise genetic distances}

The maximum clade credibility tree obtained from BEAST recovered a polyphyletic Leptogorgia divided in seven main groups (Figure 3). The western Atlantic species ( $L$. violacea, Leptogorgia sp., L. virgulata and L. gracilis) were divided into two well-supported (e.g. BP>70; PP>0.95) clades (1 and 2). The eastern Pacific species L. alba, L. cortesi, L. cuspidata, L. rigida, L. ramulus, L. styx, L. cofrini and L. chilensis grouped in a wellsupported clade (3). Western Atlantic and eastern Pacific Leptogorgia species were sister to Eugorgia, which was not monophyletic due to the exclusion of $E$. rubens and $E$. siedenburgae. Eugorgia daniana, E. multifida and E. mutabilis were placed into clade 4 with L. regis, L. taboguillae and Leptogorgia sp. (LT221106-LT221115). Leptogorgia pumila and L. tricorata nested into clade 5, which included eleven Pacifigorgia species. The Eastern Atlantic Leptogorgia species were included in a well-supported clade (6) in which Leptogorgia pulcherrima formed a monophyletic group sister to L. gaini and Leptogorgia sp. A (KY683791). These species were closely related to L. piccola, L. dichotoma, L. violetta and Leptogorgia sylvanae. The Mediterranean L. sarmentosa was sister to L. capverdensis, and both were placed into a clade including L. viminalis. The 15 South African specimens grouped into a distinct clade (7) which was sister to the eastern Atlantic representatives. Within the South African clade Leptogorgia sp. 6 was sister to the remaining species with strong support.

Pairwise genetic distances among the eastern Pacific Leptogorgia species ranged from 0 to 3\%. The genetic distances between western Atlantic and eastern Pacific Leptogorgia ranged from 1\% to 3\% (Suppl. Table S5). Genetic distances between western and eastern Atlantic species are high overall, ranging from 5\% to 6\%. Among eastern Atlantic species, the greatest genetic distance (3\%) was reported between $L$. pulcherrima, L. viminalis and $L$. capverdensis, whereas the Cape Verdean endemic L. capverdensis and L. sarmentosa shared identical haplotypes. The genetic distance between the South Africa and eastern Atlantic species ranged between 4 and 10\%. The mean pairwise genetic distances among species within the eastern Atlantic and South African clades were 1.4\%, and 2.2\%, respectively.

\subsection{Molecular dating}


Due to the use of a single fossil calibration and that some of the nodes are poorly supported (e.g. BP<70; PP<0.95), the estimated dates obtained should be interpreted with caution. According to our analyses, the divergence time between the western Atlantic Leptogorgia grouped in clade 1 and clade 2, and the eastern Pacific Leptogorgia was 28 Mya (95\% HPD: 12-48 Mya) and 23 Mya (95\% HPD: 9-35 Mya), respectively (see Fig. 3). Within clade 3, the divergence time between L. alba, L. cofrini, L. cortesi, L. styx and L. chilensis, L. ramulus, $L$. cuspidata and L. rigida was estimated at $\sim 14$ Mya (95\% HPD: 5-25 Mya). Concerning clade 4 the estimated date for the divergence between $L$. regis, L. taboguillae L. labiata, Leptogorgia sp. (LT221106 and LT221115) and Eugorgia species (e.g. E. daniana, E. multifida and E. mutabilis) was 25 Mya (95\% HPD: 11-44 Mya). Within clade 6 separation among L. viminalis, L. capverdensis and eastern Atlantic congeners occurred $~ 30$ Mya (95\% HPD: 13-57 Mya), while divergence time between the Mediterranean $L$. sarmentosa and $L$. capverdensis ranged between 0 and 6 Mya.

According to our analyses, divergence time between eastern Atlantic and South African species was estimated at 49 Mya (95\% HPD: 24-85 Mya). When considering the South African clade, Leptogorgia sp. 6, which was sister to the remaining species, diverged from its congeners between 12 and 51 Mya.

\section{Discussion}

Here, the complete mitochondrial genomes of 12 gorgonian species have been successfully exploited to assess the phylogenetic relationships within the genus Leptogorgia. Our mitogenomic analysis recovered a fully resolved and highly supported phylogeny showing the divergence between eastern Pacific L. alba, and its Caribbean, Mediterranean, eastern Atlantic and South African congeners. These results were further corroborated by the mtMutS phylogeny and support previously proposed mitochondrial phylogenetic relationships, in which eastern Atlantic Leptogorgia species, typically characterised by long, spiny and asymmetrical spindles, were found to be genetically distinct from the eastern Pacific congeners. Based on ITS2, Aguilar and Sánchez (2007) demonstrated that some of the western African taxa formerly classified as Leptogorgia spp. were separated from the western Atlantic-Caribbean congeners, and Sánchez (2007) proposed for some of them (L. angolana, L. guineensis, L. sanguinolenta and L. schoutedeni) a taxonomic reassignment to the genus Filigorgia. However this taxonomic interpretation has not been followed so far and needs a reappraisal. In line with previous authors, our phylogenetic results further point to the need of 
a comprehensive, global taxonomic revision of 'Leptogorgia', which should be split into different genera in spite of the lack of a strong morphological divergence between species from different geographic regions (e.g. eastern Atlantic vs. South African vs. western Atlantic vs. eastern Pacific).

Bayer (1956, 1961) segregated species currently included in 'Leptogorgia' in two genera (i.e. Leptogorgia and Lophogorgia) according to the presence/absence of symmetrical, asymmetrical and disk-spindle sclerites. A segregation using these characters may be appropriate to differentiate some species occurring in the western Atlantic (e.g. L. virgulata) and deserves further consideration upon revision of these fauna. The remaining species of 'Leptogorgia' pose an interesting systematic and nomenclatural problem. The genus Lophogorgia was originally proposed for the South African species L. palma and used to group 'Leptogorgia' species with symmetrical sclerites without fused warts (Bayer 1961). Lophogorgia was therefore distributed in the eastern Pacific, the Caribbean and western Atlantic and along the east coast of Africa. The deep divergence of the South African and eastern Atlantic 'Leptogorgia' clades shown here suggest that these species deserve generic recognition. In particular, the inclusion of 15 South African specimens into a well-supported clade separated from the eastern Atlantic congeners leaves no other choice but to reassign the South African members of 'Leptogorgia' to the genus Lophogorgia.

A species-level revision of the South African genus will be necessary before names can be assigned with any certainty to most of the specimens we sequenced. Williams (1992) and Williams and Lindo (1997) documented five valid species plus three species of questionable validity occurring in South Africa. Williams (1992) synonymized a number of additional species with L. palma and L. gilchristi, each of which now encompasses a wide range of different colony growth forms. Several of the taxa we sequenced have morphologies that fall within the range described for either L. palma or L. gilchristi but are genetically distinct from one another, suggesting that the current morphology-based definitions of those two species are too broad. In particular, the genetically very divergent Leptogorgia sp. 6 appears to correspond morphologically to the 'crista' variant of L. palma, formerly Lophogorgia crista. Grasshoff (1992) divided African 'Leptogorgia' into eight morphological groups based on shape and size of the colony and sclerite composition. The 'South-African' group includes four species (L. palma, L. barnardi, L. capensis and L. gilchristi), which are exclusive to the South African area. Members of the 'sarmentosa' and 'viminalis' groups have a broader geographic distribution ranging from the Mediterranean Sea to the south-western coasts of Africa. 'Sarmentosa' group includes five species, among which L. sarmentosa is limited to 
the Mediterranean basin, L. capverdensis is endemic to Cape Verde, and L. piccola and L. aureoflavescens are widespread in the central-eastern Atlantic with some records off Angola. 'Viminalis' group comprises eight species, with L. viminalis being the most common as many colonies have been reported from Gabon (Stiasny 1951), Canary Islands (Carpine and Grasshoff, 1975) and from the Mediterranean Sea (Grasshoff 1992). Two groups ('ruberrima' and 'pulcherrima') comprise single species, whereas the remaining ('dakarensis', 'sanguinolenta' and 'riodouroi') include rare and poorly studied species whose taxonomy is still uncertain. Representatives of five out of eight of Grasshoff's groups have been included here in the molecular investigations, and some of the morphological groups were not supported in our phylogenetic analyses. For instance, L. piccola was included by Grasshoff (1992) in the L. sarmentosa group but in our mtMutS phylogeny was found to be sister to the L. gaini-L. pulcherrima clade. These last two species also belong to different morphological groups, with L. pulcherrima assigned to its own group and L. gaini forming, together with $L$. dichotoma, the L. viminalis group (Grasshoff 1992). By contrast, our phylogeny recovered $L$. viminalis sister to the Mediterranean and Cape Verdean species, both of which were assigned to the L. sarmentosa group. The discrepancy between Grasshoff's morphological groups, mainly based on colony branching pattern and composition of the sclerome, and our phylogeny shows that these morphological groups are artificial, and provides another example of the homoplasic nature of characters like colony shape and sclerite compositions even at shallow taxonomic levels (i.e. intra-genus; see Ament-Velásquez et al. 2016).

The nomenclatural status of the Caribbean-western Atlantic and eastern Pacific species of 'Leptogorgia' is less clear than that of their African counterparts. The poor taxon sampling among Caribbean-western Atlantic representatives of the genus and the segregation, albeit with low support, of Caribbean-western Atlantic 'Leptogorgia' into several clades further hamper taking a clear stand regarding the taxonomic placement of these species, which are in need of revision and deserve further molecular systematic considerations. Here it is worth noting that Bayer (1961) assigned most Caribbean-western Atlantic representatives of 'Leptogorgia' to the genus Lophogorgia, and considered only four species to be part of Leptogorgia sensu stricto. At this point, is not clear whether multiple lineages deserving generic recognition exist among Caribbean-Western Atlantic 'Leptogorgia' or if the multiple clades detected with low support in our $m t M u t S$ phylogeny will remain upon the sequencing of nuclear markers or the inclusion of more species from this region.

The low genetic distances found among eastern Pacific 'Leptogorgia' species may be due to diversification events that occurred during the closure of the Central American Seaway after 
the formation of the Isthmus of Panama. This process represented a geographic barrier allowing speciation events among populations, across the Atlantic and Pacific oceans, which lasted for about 15 million years (Bacon et al. 2015). By contrast, our results showed that divergence between the western Atlantic species L. violacea and Leptogorgia sp. (USNM 1437444) and the eastern Pacific and Caribbean members occurred about 28 Mya, in agree with recent estimations on the formation of the Isthmus of Panama (see Montes et al. 2015; O'Dea et al. 2016). Previous molecular analyses using both the mtMutS and 28S rRNA have offered support for morphologically defined groups and for the existence of an eastern Pacific 'Leptogorgia' clade sister to the genus Eugorgia (Vargas et al. 2014; Ament-Velásquez et al. 2016). It is tempting to propose a new genus for L. regis and L. taboguillae, a biogeographically coherent clade which, according to our results, diverged about 25 Mya. We consider, however, that until the placement of the Caribbean-western Atlantic fauna is better resolved, and nuclear sequences of species of this region are available to corroborate eastern Pacific 'Leptogorgia' as an independent evolutionary lineage, assigning these species to a new genus may be premature.

Our fossil-calibrated divergence time estimation traced the separation of eastern and western Atlantic Leptogorgia back to the late Cretaceous ( 65 Mya), likely related to changes in the spreading geometry within the Central and South Atlantic Ocean (see e.g. Cande et al. 1988; Bosworth, 1992; Guiraud et al. 1992) and a possible decrease in gene flow between the ancestral Atlantic populations. Interestingly, the geographic clades detected show contrasting ages and divergence patterns. For instance, the low genetic distances observed among eastern Pacific 'Leptogorgia' species and their recent divergence points to a rapid diversification of these taxa. In contrast, the eastern Atlantic and South African fauna appear to have a long evolutionary history (>30 Mya) and to be composed of multiple old lineages that may deserve generic status given their large molecular divergence. This is somewhat remarkable given the morphological homogeneity observed among these species and in general in 'Leptogorgia' (see Bayer 1961 for a discussion).

The large genetic distances and the phylogenetic divergence found between the eastern Atlantic and the South African 'Leptogorgia' clades suggest an early isolation among these lineages. Indeed, according to our molecular dating analyses, separation between eastern Atlantic and South African 'Leptogorgia' ranged between 24 and $78 \mathrm{Mya}$ and the younger age for this split coincides with the enhancement of the Antarctic Circumpolar Current (ACC) and associated climate fluctuations and changes in the sea-surface temperatures. 


\section{Conclusions}

This study revealed a deep divergence among morphologically similar but geographically restricted octocoral lineages currently included in the genus Leptogorgia. Eastern Atlantic and western Atlantic octocoral clades diverged in the late Cretaceous, likely due to the spreading of the Atlantic Ocean. In addition, the changes in water circulation that occurred in the middle Paleogene in South Africa may have contributed to isolate the South African fauna from the other eastern Atlantic forms. Eastern Atlantic-Mediterranean species of 'Leptogorgia' represent an old lineage not closely related to western Atlantic-eastern Pacific 'Leptogorgia', which diverged and diversified recently. The levels of sequence divergence observed within the eastern Atlantic and South Africa 'Leptogorgia' match divergence levels observed between eastern Pacific genera, suggesting the existence of multiple lineages deserving generic status in the eastern Atlantic. This is particularly evident for the South African members, which appear to be genetically distinct from all the other eastern Atlantic 'Leptogorgia'. The clear phylogenetic separation of Leptogorgia in geographic lineages lacking clear morphological differences and sometimes displaying intermediate morphologies provides further evidence of the importance of both morphological stasis and convergent morphological evolution among gorgonians. A revision of the world 'Leptogorgia' is necessary to clarify the systematics of these organisms and provide a phylogenetically sound taxonomic system for these fauna.

\section{Acknowledgments}

We thank Thibault Rauby, Peter Southwood (Southern Underwater Research Group, Cape Town, South Africa) and "Cabo Verde Diving" for help with sampling. We are thankful to Peter Etnoyer, Andrew Shuler (NOAA) and the Smithsonian National Museum of Natural History for the material. This study was possible thanks to the generous support of the LMU München Junior Research Funds to SV through the German Excellence Initiative. SV thanks N. Villalobos Trigueros, M. Vargas Villalobos, S. Vargas Villalobos and S. Vargas Villalobos for their constant support. CM thanks B. Picton, S. Parker-Nance, E. Rodriguez and G. Zsilavecv for assisting with collections in South Africa; K. Whitfield for laboratory assistance; and the Assembling the Cnidarian Tree of Life project (U.S. National Science Foundation grants EF-0531570 to C.S. McFadden and EF-0531779 to P. Cartwright) for support. 


\section{Figures}

Figure 1 Nucleotide comparisons between the six Leptogorgia mitogenomes. A: Comparative mitogenomics including information on mitogenome size (red) and length (bp) of Coding DNA Sequence (orange), 12S rRNA and 16S rRNA genes (yellow), intergenic regions (green) and GC-content (light blue). B: Sliding window analysis on mitochondrial protein-coding genes. The black line indicates nucleotide diversity across the 14 protein-coding genes in a window of $500 \mathrm{bp}$ (10 bp steps).

Figure 2 Phylogenetic tree of the subclass Octocorallia obtained using complete mitogenomes. Roman numbers indicate the two main clades. Red letters on the branches refer to the mitochondrial gene arrangement according to Brockman and McFadden (2012). Asterisks at the nodes indicate bootstrap values $\geq 70$ (left) and posterior probabilities $\geq 0.95$ (right), respectively. Black arrows and numbers correspond to the two main groups of the family Gorgoniidae. Grey boxes include species belonging to different families such as Alcyoniidae and Nephtheidae. Gorgoniidae and Plexauridae members have been simplified under the general name of "Holaxonia". Newly sequenced samples are in bold.

Figure 3 Chronogram of the maximum clade credibility tree constructed using BEAST. Node bars show $95 \%$ highest posterior density intervals (HPD). Black circles at the nodes indicate strong support from ML (bootstrap >70) and Bayesian (posterior probabilities > 0.95). Split circles indicate low support from one analysis only (left: ML, right: Bayesian), whereas grey circles indicate low support values from both analyses. Arrows and numbers on the branches indicate node age estimates in million of years. Numbers from 1 to 7 refer to the main Leptogorgia groups. Red square indicates fossil calibration node. Scale bar on the bottom of the tree refers to million years. Western Atlantic and eastern Pacific Leptogorgia are included in grey and red boxes, respectively. Those collected from eastern Atlantic, Mediterranean and South Africa are included in light blue, green and brown boxes, respectively. Samples investigated in this study are in boldface. 


\section{References}

Aguilar, C., Sánchez, J.A., 2007. Phylogenetic hypotheses of gorgoniid octocorals according to ITS2 and their predicted RNA secondary structures. Mol. Phylogenet. Evol. 43, 774-786.

Aldous, D., 2001. Stochastic models and descriptive statistics for phylogenetic trees, from Yule to today. Stat. Sci. 16, 23-34.

Ament-Velásquez, S.L., Breedy, O., Cortés, J., Guzman, H.M., Wörheide, G., Vargas, S., 2016. Homoplasious colony morphology and mito-nuclear phylogenetic discordance among Eastern Pacific octocorals.

Mol. Phylogenet. Evol. 98, 373-381.

Andrews, S., 2010. FastQC: a quality control tool for high throughput sequence data. Available from:

http://www.bioinformatics.babraham.ac.uk/projects/fastqc.

Bacon, C.D., Silvestro, D., Jaramillo, C., Smith B.T., Chakrabarty, P., Antonelli, A., 2015. Biological evidence supports an early and complex emergence of the Isthmus of Panama. PNAS 112, 6110-6115.

Bayer, F.M., 1956. Octocorallia. In Moore, R.C. (Eds.), Treatise on Invertebrate Paleontology, part F, Coelenterata. Geological Society of America and University of Kansas Press, Lawrence, Kansas, pp. 167231.

Bayer, F.M., 1961. The shallow water Octocorallia of the West Indian Region. A manual for marine biologists. Martinus Nijhoff, The Hague, Netherlands, pp. 373.

Benson, G., 1999. Tandem repeats finder: a program to analyze DNA sequences. Nucleic Acids Res. 27, 573580.

Bernt, M., Donath, A., Juhling, F., Externbrink, F., Florentz, C., Fritzsch, G., Putz, J., Middendorf, M., Stadler, P.F., 2012. MITOS: Improved de novo metazoan mitochondrial genome annotation. Mol. Phylogenet. Evol. 69, 332-336.

Bosworth, W., 1992. Mesozoic and early Tertiary rift tectonics in East Africa. Tectonophysics, 209 (1), 115-137.

Bouckaert, R., Heled, J., Kühnert, D., Vaughan, T., Wu, C-H., Xie, D., Suchard, M.A., Rambaut, A., Drummond, A.J., 2014 BEAST 2: A software Platform for Bayesian Evolutionary Analysis. PloS Comput. Biol. 10, e1003537.

Breedy, O., Guzman H.M., 2007, A revision of the genus Leptogorgia Milne Edwards and Haime, 1857 (Coelenterata: Octocorallia: Gorgoniidae) in the eastern Pacific. Zootaxa 1419, 1-90.

Breedy, O., van Ofwegen, L.P., Vargas, S., 2012. A new family of soft corals (Anthozoa, Octocorallia, Alcyonacea) from the aphotic tropical eastern Pacific waters revealed by integrative taxonomy. Syst. Biodivers. 10 (3), 351-359.

Brockman, S.A., McFadden, C.S., 2012. The mitochondrial genome of Paraminabea aldersladei (Cnidaria: Anthozoa: Octocorallia) supports intramolecular recombination as the primary mechanism of gene rearrangement in octocoral mitochondrial genomes. Genome Biol. Evol. 4, 994-1006.

Bryce, M., Poliseno, A., Alderslade, P., Vargas, S., 2015. Digitate and capitate soft corals (Cnidaria: Octocorallia: Alcyoniidae) from Western Australia with reports on new species and new Australian geographical records. Zootaxa 3963 (2), 160-200.

Cande, S.C., La Brecque, J.L., Haxby, W.F., 1988. Plate kinematics of the South Atlantic: chron 34 to present. J. Geophys. Res. 93, 13479-13492.

Carpine, C., Grasshoff, M., 1975. Les Gorgonaires de la Méditerranée. Bulletin de l'Institut Océanographique de Monaco, 71, pp 1-140.

Cope, J.C.W., 2005. Octocorallian and hydroid fossils from the Lower Ordovician of Wales. Palaeontology 48, 433-445.

Darriba, D., Taboada, G. L., Doallo, R., Posada, D., 2012. jModelTest 2: more models, new heuristics and parallel computing. Nat. Meth. 9 (8), 772.

Edgar, R.C., 2004. MUSCLE: multiple sequence alignment with high accuracy and high throughput. Nucleic Acids Res. 32, 1792-1797.

Figueroa, D.F., Baco, A.R., 2015. Octocoral mitochondrial genomes provide insights into the phylogenetic history of gene order rearrangements, order reversals, and cnidarian phylogenetics. Genome Biol. Evol. 7 , 391-409.

France, S.C., Hoover L.L., 2002. DNA sequences of the mitochondrial COI gene have low levels of divergence among deep-sea octocorals (Cnidaria: Anthozoa). Hydrobiologia 471, 149-155. 
Gernhard, T., 2008. The conditioned reconstructed process. J. Theor. Biol. 253, 769-778.

Giammona, C.P., Robert Jr., J.S., 1980. Octocorals from the Middle Eocene Stone City Formation, Texas. J. Paleontol. 54, 71-80.

Grabherr, M.G., Haas, B.J., Yassour, M., Levin, J.Z., Thompson, D.A., Amit, I., Adiconis, X., Fan, L., Raychowdhury, R., Zeng, Q., Chen, Z., Mauceli, E., Hacohen,N., Gnirke, A., Rhind, N., di Palma, F., Birren, B.W:, Nusbaum, C., Lindblad-Toh, K., Friedman, N., Regev, A., 2011. Full-length transcriptome assembly from RNA-Seq data without a reference genome. Nat. Biotechnol. 29, 644-652.

Grasshoff, M., 1988. The genus Leptogorgia (Octocorallia: Gorgoniidae) in West Africa. Atlantide Report 14, 91-147.

Grasshoff, M., 1992. Die Flachwasser - Gorgonarien von Europa und Westafrika (Cnidaria, Anthozoa). Courier Forschungsinstitut Senckenberg 149, 1-135.

Guiraud, R., Binks, R.M., Fairhead, J.D., Wilson, M., 1992. Chronology and geodynamic setting of CretaceousCenozoic rifting in West and Central Africa. Tectonophysics, 213 (1), 227-234.

Huang, D., Meier, R., Todd, P.A., Chou, L.M., 2008. Slow mitochondrial COI sequence evolution at the base of the metazoan tree and its implications for DNA barcoding. J. Mol. Evol. 66, 167-174.

Kearse, M., Moir, R., Wilson, A., Stones-Havas, S., Cheung, M., Sturrock, S., Buxton, S., Cooper, A., Markowitz, S., Duran, C., Thierer, T., Ashton, B., Mentjies, P., Drummond, A., 2012. Geneious Basic: an integrated and extendable desktop software platform for the organization and analysis of sequence data. Bioinformatics 28, 1647-1649.

Kocurko, M.J., Kocurko, D.J., 1992. Fossil Octocorallia of the Red Bluff Formation, Lower Oligocene, Mississippi. J. Paleontol. 66, 594-602.

Lanfear, R., Calcott, B., Ho, S.Y.W., Guindon, S., 2012 PartitionFinder: combined selection of partitioning schemes and substitution models for phylogenetic analyses. Mol. Biol. Evol. 29, 1695-1701.

Librado, P., Rozas, J., 2009. DnaSP v5: A software for comprehensive analysis of DNA polymorphism data. Bioinformatics 25, 1451-1452.

Maricic, T., Whitten, M., Pääbo, S., 2010. Multiplexed DNA Sequence Capture of Mitochondrial Genomes Using PCR Products. PLoS ONE 5, e14004.

Malecki, J., 1982. Bases of upper cretaceous octocorals from Poland. Acta Palaeontol. Pol. 27, 65-75.

McFadden, C.S., France, S.C., Sánchez, J.A., Alderslade, P., 2006. A molecular phylogenetic analysis of the Octocorallia (Cnidaria: Anthozoa) based on mitochondrial protein coding sequences. Mol. Phylogenet. Evol. 41, 513-527.

McFadden, C.S., Benayahu, Y., Pante, E., Thoma, J.N., Nevarez, P.A., France, S.C., 2011. Limitations of mitochondrial gene barcoding in the cnidarian sub-class Octocorallia. Mol. Ecol. Resour. 11, 19-31.

McFadden, C.S., van Ofwegen L.P. 2012. Stoloniferous octocorals (Anthozoa, Octocorallia) from South Africa, with descriptions of a new family of Alcyonacea, a new genus of Clavulariidae, and a new species of Cornularia (Cornulariidae). Invertebr. Syst. 26, 331-356.

McFadden, C.S., van Ofwegen L.P. 2013. Molecular phylogenetic evidence supports a new family of octocorals and a new genus of Alcyoniidae (Octocorallia, Alcyonacea). Zookeys 346, 59-83.

Montes, C., Cardona, A., Jaramillo, C., Pardo, A., Silva, J.C., Valencia, V., Ayala, C., Pérez-Angel, L.C., Rodriguez-Parra, L.A., Ramirez, V., Niño, H., 2015. Middle Miocene closure of the Central American seaway. Sciene 348, 226-229.

O’Dea, A., Lessios, H.A., Coates, A.G., Eytan, R.I., Restrepo-Moreno, S.A., Cione, A.L., Collins, L.S., de Queiroz, A., Farris, D.W., Norris, R.D., Stallard, R.F., Woodburne, M.O., Aguilera, O., Aubry, M.P., Berggren, W.A., Budd, A.F., Cozzuol, M.A., Coppard, S.E., Duque-Caro, H., Finnegan, S., Gasparini, G.M., Grossman, E.L., Johnson, K.G., Keigwin, L.D., Knowlton, N., Leigh, E.G., Leonard-Pinge, J.S., Marko, P.B., Pyenson, N.D., Rachello-Dolmen, P.G., Soibelzon, E., Soibelzon, L., Todd, J.A., Vermeij, G.J., Jackson, J.B.C. 2016. Formation of the Isthmus of Panama. Science Advances 2, e1600883.

Park, E., Song, J.I. and Won, Y.J., 2011. The complete mitochondrial genome of Calicogorgia granulosa (Anthozoa: Octocorallia): potential gene novelty in unidentified ORFs formed by repeat expansion and segmental duplication. Gene 486, 81-87.

Park, E., Hwang, D.S., Lee, J.S., Song, J.I., Seo, T.K., Won, Y.J., 2012. Estimation of divergence times in cnidarian evolution based on mitochondrial protein-coding genes and the fossil record. Mol. Phylogenet. Evol. 62, 329-345.

Poliseno, A., Breedy, O., Eitel, M., Woerheide, G., Guzman, H.M., Krebs, S., Blum, H., Vargas S. 2016. Complete mitochondrial genome of Muricea crassa and Muricea purpurea (Anthozoa: Octocorallia) from the eastern tropical Pacific. BioRxiv doi: http://dx.doi.org/10.1101/042945.

Porebski, S., Bailey, L.G., Baum, B., 1997. Modification of a CTAB DNA extraction protocol for plants containing high polysaccharide and polyphenol components. Plant Mol Biol Rep. 15, 8-15.

Rambaut, A., Suchard, M.A., Xie, D., Drummond, A.J., 2014. Tracer v1.6. Available from http://beast.bio.ed.ac.uk/Tracer. 
Ronquist, F., Huelsenbeck J., 2003. MrBayes 3: Bayesian phylogenetic inference under mixed models. Bioinformatics 19, 1572-1574.

Sánchez, J.A., McFadden, C.S., France, S.C., Lasker H.R., 2003. Molecular phylogenetic analyses of shallowwater Caribbean octocorals. Mar. Biol. 142, 975-987.

Sánchez, J.A., 2007. A new genus of Atlantic octocorals (Octocorallia: gorgoniidae): systematics of gorgoniids with asymmetric sclerites. J. Nat. Hist. 41 (9-12), 493-509.

Stiasny, G., 1951. Alcyonides et Gorgonides des collections du Muséum national d'Histoire naturelle (II). Mém. Mus. natn. Hist. nat., (A, Zool.) 3 (1), 1-80.

Tamura, K., Stecher, G., Peterson, D., Filipski, A., Kumar, S., 2013. MEGA6: Molecular Evolutionary Genetics Analysis Version 6.0. Mol. Biol. Evol. 30, 2725-2729.

Timmermans, M.J.T.N., Dodsworth, S., Culverwell, C.L., Bocak, L., Ahrens, D., Littlewood, D.T.J., Pons, J., Vogler, A.P., 2010. Why barcode? High-throughput multiplex sequencing of mitochondrial genomes for molecular systematics. Nucleic Acids Res. 38, 1-14.

Vargas, S., Eitel, M., Breedy, O., Schierwater, B., 2010. Molecules match morphology: mitochondrial DNA supports Bayer's Lytreia-Bebryce-Heterogorgia (Alcyonacea: Octocorallia) clade hypothesis. Invertebr. Syst. 24, 23-31.

Vargas, S., Guzman, H.M., Breedy, O., Wörheide G., 2014. Molecular phylogeny and DNA barcoding of tropical eastern Pacific shallow-water gorgonian octocorals. Mar Biol. 161, 1027-1038.

Verrill, A. E., 1868. Notes on Radiata in the Museum of Yale College, Number 6: Review of the corals and polyps of the West Coast of America. Transactions of the Connecticut Academy of Arts and Sciences 377422.

Williams, G.C., 1992. The Alcyonacea of southern Africa. Gorgonian octocorals (Coelenterata, Anthozoa). Annals of the South African Museum 101, 181-296.

Williams, G.C., Lindo, K.G., 1997. A review of the octocorallian genus Leptogorgia (Anthozoa: Gorgoniidae) in the Indian Ocean and Subantarctic, with description of a new species and comparisons with related taxa. Proceedings of the California Academy of Sciences 49, 499-521.

Wirshing, H.H., Baker, A.C., 2015. Molecular and morphological species boundaries in the gorgonian octocoral genus Pterogorgia (Octocorallia: Gorgoniidae). PLoS ONE 10, e0133517. 


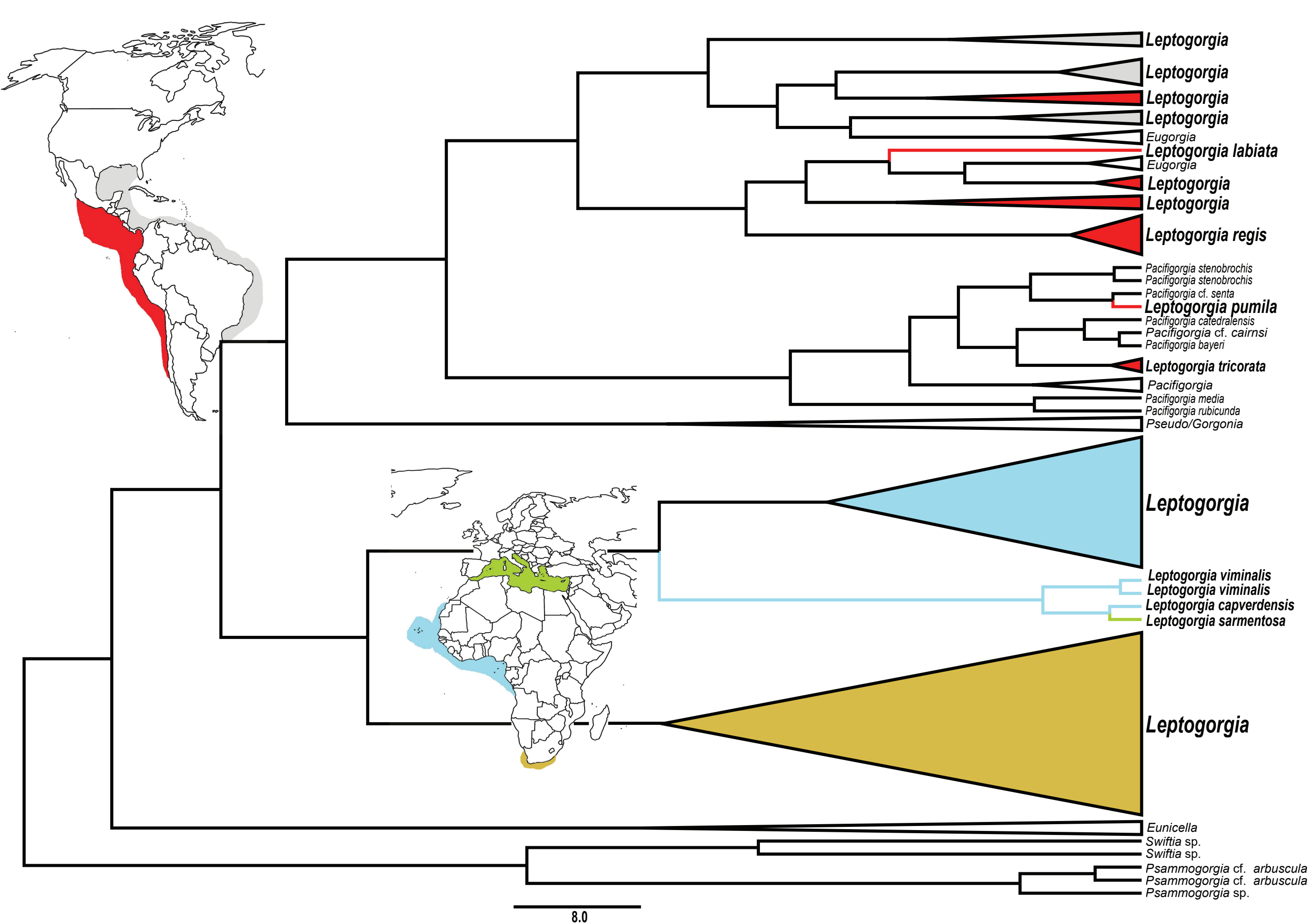




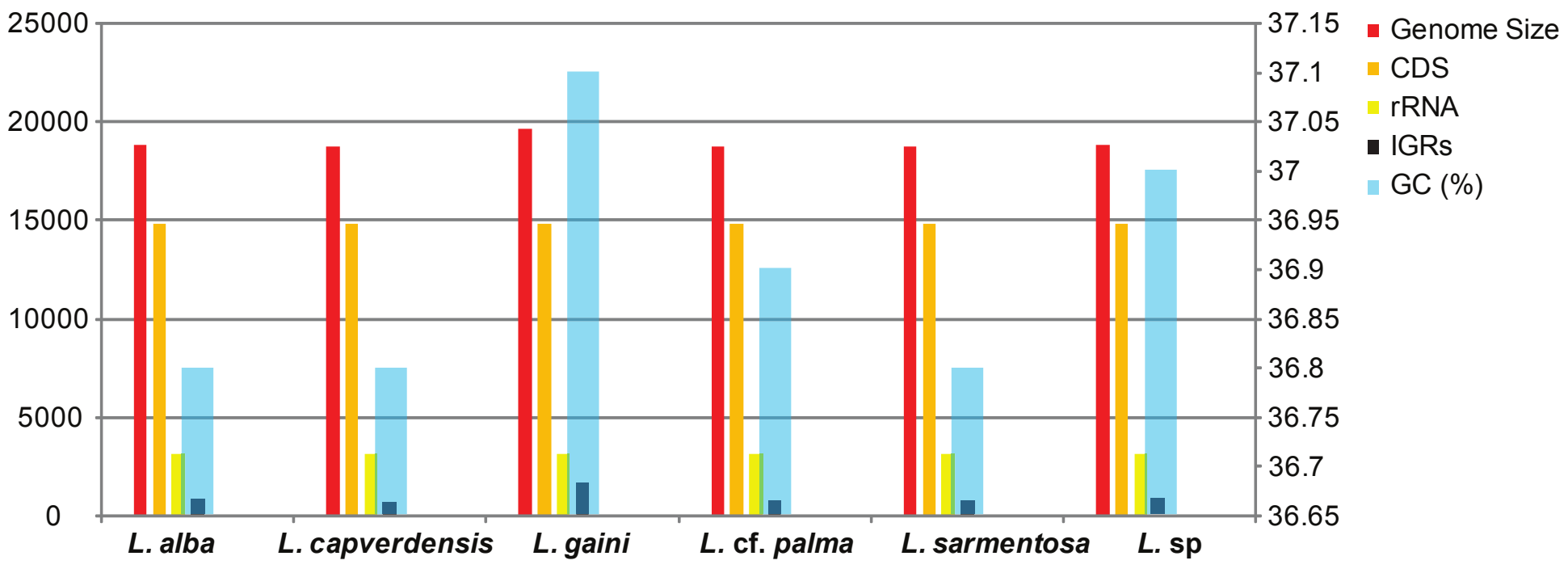

\section{nucleotide} variation per site

\section{Nucleotide diversity}

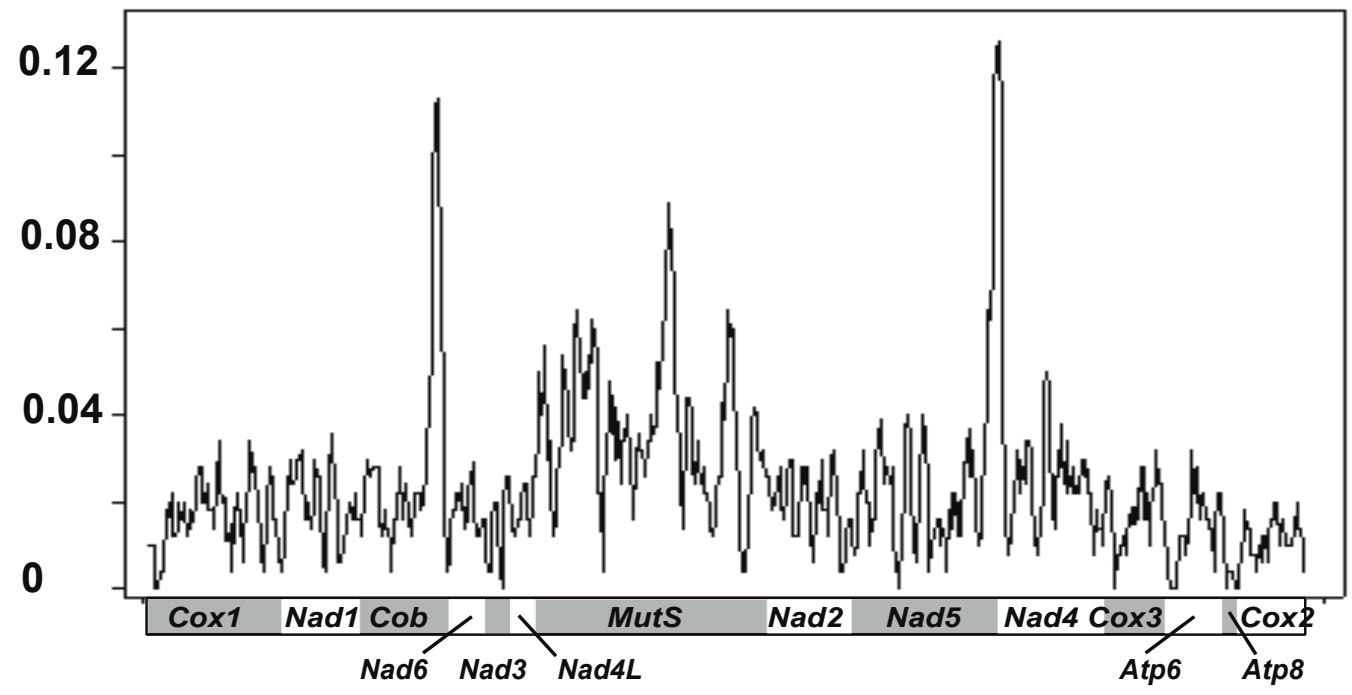



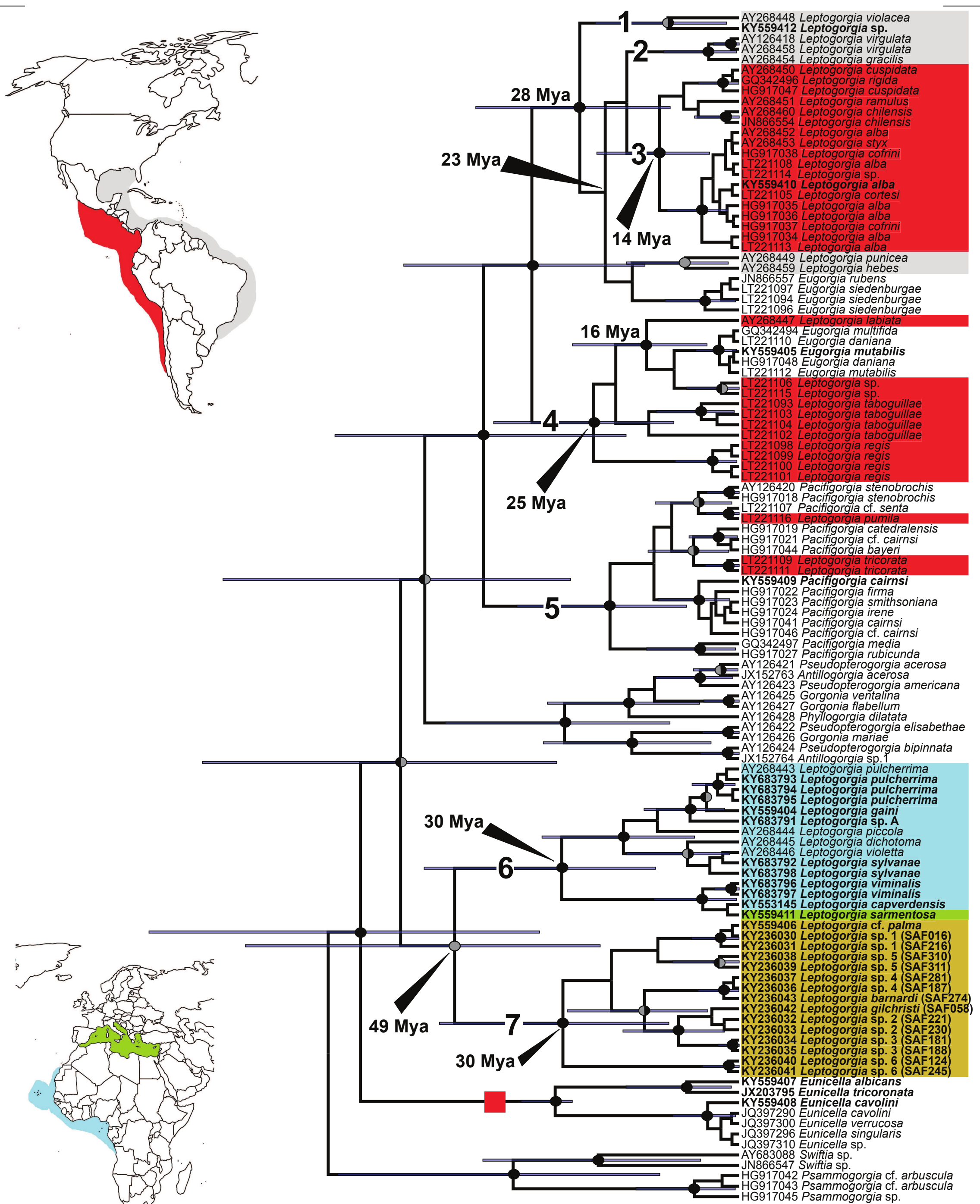

गु

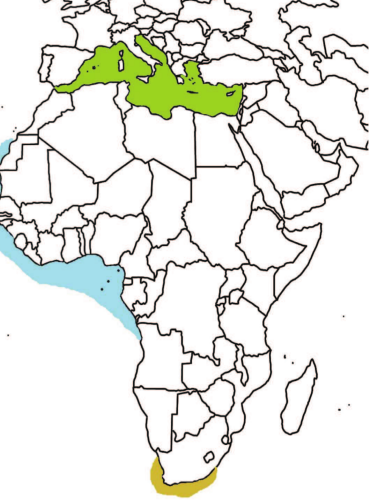

